\title{
Off-label medicine use: ethics, practice and future directions
}

Background: Medicine use is considered off-label when used for an indication, at a dose, via a route of administration or in a patient group not included in the approved product information. Off-label use varies according to therapeutic class and patient group, and often occurs in those who are vulnerable.

Objective: To discuss ethical, practice and policy considerations associated with off-label medicine use.

Discussion: A number of professional organisations have issued guidance in relation to offlabel medicine use. Prescribers should inform patients and document consent when prescribing off-label. This should include an open discussion about known and unknown benefits and risks. The prescriber should document the reason for off-label use in the patient's record and ensure that patients are aware of the intended duration and relevant monitoring. Australia's new national health priority of Quality Use of Medicine and Medicine Safety should stimulate all stakeholders including consumers to work together to address off-label medicine use.

Since Quality Use of Medicine and Medicine Safety was declared a national health priority there has been renewed focus on off-label medicines use. Writing in The Australian in May 2020, Julian Hill MP highlighted the need for Australia to maintain its world class medicine safety regime. ${ }^{1}$ This follows Mr Hill's call for an independent inquiry into Australia's pharmacovigilance system after his daughter experienced deep vein thrombosis linked to off-label oral contraceptive use. ${ }^{2}$ Mr Hill's daughter is not alone in experiencing medicinesrelated harm. In Australia, medicines-related harm is linked to an estimated 250,000 hospital admissions and 400,000 emergency department presentations each year. ${ }^{3}$ Of all preventable harm in healthcare, medicines account for the highest proportion. ${ }^{4}$

Medicine use is considered off-label when used for an indication, at a dose, via a route of administration, or in a patient group that is not included in the product information approved by the Therapeutic Goods Administration (TGA). ${ }^{5,6}$ While the majority of prescribers and pharmacists are familiar with the term 'off-label prescribing', awareness among patients is low. ${ }^{7}$ Not all off-label medicine use is inappropriate, and there are conditions for which an off-label medicine is the treatment of choice. ${ }^{8}$ However, patients should be informed that their treatment is off-label and be engaged in a full and open discussion regarding benefits and risks.

The proportion of medicine use that is considered off-label varies by therapeutic class and patient group. An estimated $40-75 \%$ of antipsychotic use among adults and $36-93 \%$ of use among children is considered off-label. ${ }^{9}$ Off-label antipsychotic use includes prescribing of quetiapine for insomnia and anxiety, and risperidone and aripiprazole for ADHD, anxiety and mood disorders. The antidepressant mirtazapine and antiepileptics gabapentin and pregabalin are often prescribed off-label for insomnia. ${ }^{10} \mathrm{High}$ rates of off-label antipsychotic, antidepressant and antiepileptic medications can be attributed to the exclusion of people with mental health disorders from randomised controlled trials (RCTs), overlap in symptoms between different mental health disorders, and high rates of treatment switching within and between medicine classes. ${ }^{8}$

Of concern, off-label medicine use often occurs among vulnerable patient groups (e.g. older people, children, people with mental health disorders). The term 'therapeutic orphan' is sometimes applied to describe infants, children and pregnant women for whom there is a lack of research on treatment efficacy and safety. ${ }^{6}$ Even when vulnerable patient groups are included in RCTs, the participant sample size is often too small to conduct adequately 
powered sub-analyses, particularly in relation to rare adverse drug events. This means that there is often lack of safety data to inform prescribing for these specific patient groups.

Off-label medicine use is not a new issue. Rates of off-label medicine use in children have remained persistently high since $1996 .{ }^{11}$ However, with medicine safety now a national health priority there is renewed professional and public interest. The interim report of Royal Commission into Aged Care Quality and Safety published in October 2019 raised important concerns regarding the off-label use of psychotropic medicines among residents of aged care homes, particularly among those with dementia. ${ }^{12}$

There are important clinical and ethical considerations associated with prescribing off-label. A number of professional bodies have issued advice in relation to off-label prescribing. In 2018, the Australian and New Zealand College of Psychiatrists has issued a professional practice guidance on off-label prescribing. ${ }^{13}$ This includes explaining the benefits and risks, obtaining and documenting informed consent, documenting the reason for off-label use in the patient's record, and ensuring that general practitioners and patients are aware of the intended duration and relevant monitoring. In 2013, the Council of Australian Therapeutic Advisory Groups published guidance related to off-label medicine use within Australian hospitals. ${ }^{14}$ This guidance was adapted from earlier consensus recommendations that highlight the importance of assessing evidence for appropriateness of use and obtaining patient consent. ${ }^{15}$

Most US physicians agree that off-label medicine use should not be promoted. ${ }^{16}$ Both the United States (US) Food and Drug Administration (FDA) and Australian TGA prohibit advertising for off-label indications to prescribers or the general public. There are calls for Australia to go further. Julian Hill MP has called for a public inquiry into off-label prescriptions, and called on prescribers to notify pharmacists whenever a medicine is prescribed off-label.

There are a number of new approaches worthy of consideration. This may include the prescriber entering the indication into prescribing software or a patient's electronic health record. Pharmacists often attach Cautionary Advisory Labels (CALs) when dispensing specific products. In June 2020, a new CAL was implemented for opioids warning patients about the risk of overdose and dependence. ${ }^{17}$ Given that patients and professional bodies recognise the importance of informed consent, consideration could be given to developing a new CAL for medicines that are prescribed and dispensed off-label. Successful implementation of this approach would require the pharmacist and patient to be made aware of the indication as advocated by Mr Hill. Stakeholder consultation about the professional and patient acceptability of this approach would be necessary.

One reason for persistent high rates of off-label use is the lack of incentives for pharmaceutical companies to seek approval for new indications, particularly if the anticipated revenue does not offset the time and cost of undertaking additional research and obtaining regulatory approvals. ${ }^{6}$ Post-marketing observational studies utilising administrative data and electronic medication records are an important and under-recognised component of our pharmacovigilance system. Rapid and widespread uptake of electronic medication record systems studies is transforming research into medicine safety and effectiveness. ${ }^{18}$ These observational studies have potential to address evidence gaps specific to vulnerable population groups and rare adverse events. This includes conducting multidatabase pharmacoepidemiological studies using Australian and international data to overcome issues related to small sample sizes when investigating treatment of rare conditions or adverse events.

Declaring Quality Use of Medicine and Medicine Safety a national health priority should provide the impetus for all stakeholders to unite and implement strategies to minimise 
treatment risk and maximise effectiveness, regardless of the indication, dose, route of administration or patient group. Understanding the benefits and risks of off-label medicines should be a focus in Australia. In the meantime, we urge prescribers to continue using shared decision making to ensure patients are aware when a medicine is being prescribed off-label, what off-label use means, and are informed of the known and unknown benefits and risks. 


\section{References}

1. Hill J. Off-label drugs a risky business. The Australian Available at URL: https://www.theaustralian.com.au/commentary/offlabel-drugs-a-risky-business/newsstory/649838d1e11f435cb628fbbee3df5348 [Accessed Aug 8, 2020]

2. Brooker C. Off-label drugs under the spotlight. Aust J Pharm 2019. Available at URL: https://ajp.com.au/news/off-label-scripts-under-the-spotlight/ [Accessed Aug 8, 2020]

3. Pharmaceutical Society of Australia (2019) Medicine Safety: Take Care. Available at URL: https://www.psa.org.au/wp-content/uploads/2019/01/PSA-Medicine-SafetyReport.pdf [Accessed Aug 8, 2020]

4. Panagioti M, Khan K, Keers RN, Abuzour A, Phipps D, Kontopantelis E, Bower P, Campbell S, Haneef R, Avery AJ, Ashcroft DM. Prevalence, severity, and nature of preventable patient harm across medical care settings: systematic review and metaanalysis. BMJ 2019;366:14185

5. Seale JP. Off-label prescribing. Med J Aust. 2014;200(2):65-65

6. Gray SG, McGuire TM. Navigating off-label and unlicensed medicines use in obstetric and paediatric clinical practice. J Pharm Pract Res 2019;49(4):389-395

7. Balan S, Hassali MA, Mak VS. Awareness, knowledge and views of off-label prescribing in children: a systematic review. Br J Clin Pharmacol 2015;80(6):1269-80

8. Wittich CM, Burkle CM, Lanier WL. Ten common questions (and their answers) about off-label drug use. Mayo Clin Proc. 2012;87(10):982-990

9. Carton L, Cottencin O, Lapeyre-Mestre M, Geoffroy PA, Favre JM, Simon N, Bordet $\mathrm{R}$, Rolland B. Off-label prescribing of antipsychotics in adults, children and elderly individuals: a systematic review of recent prescription trends. Curr Pharm Des. 2015;21(23):3280-97

10. Grima NA, Bei B, Mansfield D. Insomnia management. Aust J Gen Pract. 2019; 48(4):198-202

11. Balan S, Hassali MAA, Mak VSL. Two decades of off-label prescribing in children: a literature review. World J Pediatr. 2018;14(6):528-540

12. Royal Commission into Aged Care Quality and Safety (2019). Interim Report: Neglect. Available at URL: https://agedcare.royalcommission.gov.au/publications/interim-report [Accessed Aug 8, 2020]

13. Royal Australian and New Zealand College of Psychiatrists (2019). Professional Practice Guideline 4: 'Off-label' prescribing in psychiatry. Available at URL: https://www.ranzcp.org/files/resources/college statements/practice guidelines/ppg4-off-label-prescribing-in-psychiatry.aspx [Accessed Aug 8, 2020]

14. Council of Australian Therapeutic Advisory Groups (2013). Rethinking medicines decision-making in Australian hospitals: guiding principles for the quality use of offlabel medicines. Available at URL: http://www.catag.org.au/wpcontent/uploads/2012/08/OKA9963-CATAG-Rethinking-Medicines-Decision-Makingfinal1.pdf [Accessed Aug 8, 2020]

15. Gazarian M. Kelly M, McPhee JR, Graudins LV, Ward RL, Campbell TJ. Off-label use of medicines: consensus recommendations for evaluating appropriateness. Med J Aust. 2006;185(10):544-8

16. Kesselheim AS, Woloshin S, Zhigang L, Tessema FA, Ross KM, Schwartz LM. Physicians' perspectives on FDA approval standards and off-label drug marketing. JAMA Intern Med. 2019;179(5):707-709

17. Woodley M. newsGP. Pharmacists to add warning labels to opioids. Available at URL: https://www1.racgp.org.au/newsgp/clinical/pharmacists-to-add-warning-labelson-opioids [Accessed Aug 8, 2020]

18. Ilomäki J, Lai EC, Bell JS. Using clinical registries, administrative data and electronic medical records to improve medication safety and effectiveness in dementia. Curr Opin Psychiatry 2020;33(2):163-169 